\title{
Safety of Health Workers: a Key Priority in COVID-19 Pandemic
}

Bhakta Bahadur KC*

Author Info:

Ministry of Health and Population, Nepal

\section{Corresponding Author:}

Dr. Bhakta Bahadur KC

Email/Contact:

bhaktakc52@gmail.com

\section{ABSTRACT}

Although, the health workforce is one of the most significant building blocks of the health system, the preparation to ensure safety from COVID-19 remains inadequate across the world. Therefore, there is a growing number of health workers being infected from COVID-19 globally, making health workers the most vulnerable population to the pandemic. Most of the countries lack adequate and quality personal protective equipment in health care settings resulting in high exposure of health workers to this fatal SARS-COV2. Besides these, sometimes, health workers' own negligence on adopting safety behaviours is also contributing infection to themselves. A high-level political commitment together with the investment in the health sectors to increase the supply of protective gear and capacity building of health workers is key to save and to reduce the risk of getting infected from COVID-19 pandemic.

\section{Keywords:}

Safety, Health worker, COVID-19, Pandemic, PPE (Personal Protective Equipment)

\section{Article Info}

Scan Me for Full Text

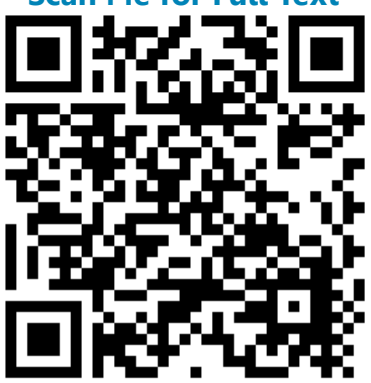

s. View PDF How to cite this article in Vancouver Style? 2(COVID-19 Special Issue): 89-92. https://doi.org/10.46405/ejms.v2i2.96

\section{Disclaimer}

Conflict of Interest: None Declared; the original work is properly cited.

Received: 21 July 2020； Accepted: 20 September 2020; Published Online: 21 September 2020

KC BB. Safety of health workers: a key priority in COVID-19 pandemic. Europasian J Med Sci. 2020;

Source of Support: Nil

Copyright: () 2020 by author(s). This is an open access article distributed under the terms of the Creative Commons Attribution International License 4.0 (http://creativecommons.org/licenses/ by/4.0/) which permits unrestricted use, distribution, and reproduction in any medium, provided

\section{Publisher's Note}

The Europasian Journal of Medical Sciences (EJMS) (www.europasianjournals.org) is an official Journal of Nirvana Psychosocial Care Center \& Ressearch Institute (www.nirvanapscc.com). The Journal as well as publisher remain neutral with regards to any jurisdictional claims in any published articles, its contents and the institutional affiliations of the authors. 


\section{INTRODUCTION}

As of July 4, 2020, COVID-19 has infected more than 11 million people worldwide and has killed more than five hundred thirty thousand people so far. ${ }^{1}$ This COVID-19 pandemic, the worst crisis after world war II, initially originated from Wuhan, China, has spread almost every corner of the globe. ${ }^{2}$ In this pandemic, almost all countries globally adopted lockdown to contain the virus and people are told to stay at home while health workers on the other hand are obliged to go to work.

Coronavirus, being a novel virus, very little was known about it and thus China had a hard time in combating and containing the epidemic. Initially, it was thought to be transmitted from animals only and human to human transmission was not known until very late. Fomite transmission was discovered later, and the full picture regarding the modes of transmission of the virus is yet to be discovered. Later on, it was known that the disease has likely to have about three to four times transmissibility (basic reproduction ratio). ${ }^{3}$ Amid those preliminary knowledge about COVID-19, the disease has already infected many people and health workers and now has emerged as a global pandemic.

From the very beginning of the epidemic of COVID-19 to the latest pandemic, the health workers at the frontline of the management of the disease have been at the highest risks, many have become disproportionately infected and many have died. In China, Li Wenliang, the first doctor who informed the risks and seriousness of the disease with his colleagues, was infected with the disease, died from the coronavirus. ${ }^{4}$ Many other health workers then became infected with the disease. When a large number of health workers got infected, the public health system in Wuhan was likely in a state of failure. In addition to this, health officials were also skeptical about whether the war with COVID could be won. In Italy, almost $11 \%$ of total COVID cases comprises health workers. ${ }^{5,6}$

As of April 8, 2020, the World Health Organization(WHO)reported that more than 22,000 health workers worldwide have been infected with COVID-19.7 Thereafter, the WHO has not updated the status of infection of health workers from COVID-19. According to the CDC report on April 15 , more than 10,000 health workers in the United States were infected while as of report on May 27, more than 60,000 health workers are infected with the disease. ${ }^{8}$ As per the report of the International Council for Nursing on 6 May, it is estimated that at least 90,000 health workers are currently infected with this disease globally. ${ }^{9}$ Again as per the next report of the ICN, as many as 230,000 health workers have been estimated to be infected..$^{10}$ In the case of Nepal, at least 34 health workers were reportedly infected from the virus until June 17, 2020, in Nepal. ${ }^{11}$ However, this number appears to be triple within just about 15 days. ${ }^{12}$ Currently more than 600 health workers working in the Kathmandu valley alone are found to be infected from COVID. ${ }^{13}$ Undoubtedly, these figures from different organizations could help to estimate that currently, the real figure of infected health workers is likely to be far larger than these figures.

Health workers are an important and integral part of the six-building block of the health system, without which the health system and healthcare delivery cannot be imagined. ${ }^{14}$ The health workers who suffered from most of the other infections can continue their services but this is such a contagious infection in which the health worker can no longer engage in healthcare services once he or she is infected. Rather, they have to leave the service immediately after they tested positive of COVID-19.15 Sometimes all the health workers and other employees of the health organization have to be in quarantine or isolation, and in that case, another team has to take their place to continue the healthcare delivery. This is a very challenging and difficult situation, especially for those countries with poor health systems with inadequate health workers.

The factors associated with the increased number of health workers being infected with COVID-19 could be broadly categorized into PPE (Personal Protective Equipment) related and non-PPE related. Lack of PPE, substandard PPE, lack of knowledge about donning and doffing of PPE, irrational use of PPE are among the PPE related causes while exposure to extended time, psychological stress, burnout, lack of resources for infection prevention and control system, negligence on protecting themselves are some of the other causes that are likely to increase the susceptibility of infection to the health workers. ${ }^{16-20}$

\section{WAY FORWARD}

\section{Increase the supply of PPE}

Just as no war in the world can be won without a healthy, well-equipped and confidence security forces, we cannot win this epidemic if we do not mobilize health workers with adequate personal protective equipment and resources. Even if we 
achieve the victory, we will incur a lot of damage. A victory with many losses is a defeat in a nutshell. Therefore, we can win the war against this disease only if we protect health workers by making the PPE available in adequate quantities with rationale use. Similarly, the gap of the PPE must be fulfilled by establishing the in-country production mechanism as soon as possible.

\section{Provide High Value to Health workers}

Human resources for health are trained and competent manpower with knowledge and skills on the management of health emergencies like COVID-19. Thus, they cannot be replaced, and losing them could cause a massive loss to the health system Because of this, the Royal College of Nursing in the United Kingdom told nursing staff that they should refuse service if there are health and safety hazards like lack of PPE. It also reported that if such weakness is found, then the RCN would help in the path of legal treatment. ${ }^{17}$ In Nepal, the number of COVID-19 positive cases are in increasing order, which needs several health workers deployment in the treatment of the infected. Therefore, everyone should give priority to health workers to increase their morale.

\section{Health workers' self-responsibility}

Health workers also need to be sensitive and responsible for their safety. Every health workers must follow the established occupation safety procedures while caring for the patients together with the monitoring system in place. ${ }^{18}$ Besides this, the risk assessment should be performed every time in the health care setting. The infection seen in more than 60,000 health workers in the USA alone shows that every health worker should remain in high alert given that it can infect any of us.

\section{Capacity building}

Trainings to the health workers regarding COVID-19 have been conducted in Nepal. However, this is not adequate in reaching to all health workers. Recent studies have shown that many health workers have been infected from COVID-19 due to a lack of adequate knowledge, practices, and training regarding infection prevention and control. 19,20 $^{2}$ Therefore, there must be an established continuous training on COVID-19 to all health workers to empower them to fight as well as to make them safe from COVID-19.

\section{Political commitment}

It is the responsibility and duty of the state to ensure safety equipment to the health workers assigned to the frontline in the management of COVID-19. This can be achieved by making a firm political commitment to the safety of health workers and implementing it. Furthermore, the health facilities must have a strong surveillance system in place to get information about the implementation status of infection prevention guidance within the health facilities.

Besides these, the governments should think about the health workers beyond just protection from the infection of COVID-19. They also consider the impact level of the COVID-19 infection and must secure the societal responsibility towards the health workers and their families. For this, securing COVID insurance, compensation to the health worker, and family members for DALYs (disability adjusted life years) of COVID are critical for the overarching safety and security of the health workers. These interventions ultimately might increase the high morale of the health workers, leading to success in infection control.

\section{CONCLUSION}

Human resources for health is a critical and integral part of the health system and is the most suffered population from COVID-19. They must be saved from infection through the collective proactive measures as well as kept them in high morale from the government, non-government and private sector, and civil society.

\section{REFERENCES}

1. Worldometer Coronavirus. 2020; https://www. worldometers.info/coronavirus/? Accessed July 4, 2020.

2. WHO. Coronavirus disease (COVID-19) Pandemic. Accessed March 15, 2020. [Link]

3. Liu Y, Gayle AA, Wilder-Smith A, Rocklöv J. The reproductive number of COVID-19 is higher compared to SARS coronavirus. Journal of travel medicine. 2020. https://doi.org/10.1093/jtm/ taaa021 Google Scholar PMC Full Text

4. GreenA.Liwenliang. The Lancet.2020;395(10225):682. https://doi.org/10.1016/S0140-6736(20)30382-2 Google Scholar Full Text

5. Livia Borghese VDD, Nicola Ruotolo and John Fiegener. Nearly 1 in 10 of Italy's infected are health care workers. Accessed September 19, 2020. [Link]

6. Epicentro. COVID-19 integrated surveillance data in Italy. In: Health EoP, ed2020. Accessed September 19, 2020. [Link]

7. World Health O. Coronavirus disease 2019 (COVID-19): situation report, 82. 2020. Google 


\section{Scholar Full Text}

8. CDC. Cases \& Deaths among Healthcare Personne. 2020. Accessed May 28, 2020. [Link]

9. ICN calls for data on healthcare worker infection rates and deaths. 2020. [press release]. 2020. https:// www.icn.ch/news/icn-calls-data-healthcare-workerinfection-rates-and-deaths Accessed May 20, 2020.

10. Over 230,000 health workers infected with virus: Study. 2020. Accessed July 4, 2020. [Link]

11. Health workers are high risk of covid-19. Nepal Samachar Patra June 17, 2020. Accessed June 25, 2020.

12. Poudel A. 91 health workers across the country have been infected with coronavirus so far. The Kathmandu Post. July 3, 2020.

13. More than 600 health workers are infected in the Kathmandu Valley alone. Nepal Samacharpatra 2020. Accessed September 19,2020. [Link]

14. Anand $S$, Bärnighausen T. Health workers at the core of the health system: framework and research issues. Health Policy. 2012;105(2-3):185-191. https:// doi.org/10.1016/j.healthpol.2011.10.012 Google Scholar Pubmed Full Text
15. WHO. What's needed now to protect health workers: WHO COVID-19 briefing. 2020. Accessed April 15, 2020. [Link]

16. Malhotra N, Gupta N, Ish S, Ish P. COVID-19 in intensive care. Some necessary steps for health care workers. Monaldi Archives for Chest Disease. 2020;90(1). DOI: 10.4081/monaldi.2020.1284 Google Scholar Pubmed Full Text

17. Refusal to treat. 2020; https://www.rcn.org.uk/gethelp/rcn-advice/refusal-to-treat. Accessed April 15, 2020

18. World Health O. Coronavirus disease (COVID-19) outbreak: rights, roles and responsibilities of health workers, including key considerations for occupational safety and health. World Health Organization, Interim guidance. 2020;19.. Accessed May 1, 2020. Google Scholar Full Text

19. Wang J, Zhou M, Liu F. Reasons for healthcare workers becoming infected with novel coronavirus disease 2019 (COVID-19) in China. J Hosp infect. 2020;105(1). https://doi.org/10.1016/j.jhin.2020.03.002 Google Scholar Pubmed PMC Full Text

20. Panthy L, Panthi J, Amgain K, Thapaliya P, Van Laar J. COVID-19 in Nepal: Scarcity of Personal Protective Equipment (PPE) and its Alternative. Europasian Journal of Medical Sciences. 2020 May 4;2(1):7480. https://doi.org/10.46405/ejms.v2i1.47 [Google Scholar] 